\title{
Correction to: The dysregulated innate immune response in severe COVID-19 pneumonia that could drive poorer outcome
}

\author{
Mathieu Blot ${ }^{1,2^{*}}$, Jean-Baptiste Bour ${ }^{3}$, Jean Pierre Quenot ${ }^{2,4,5,6}$, Abderrahmane Bourredjem ${ }^{5,6}$, \\ Maxime Nguyen ${ }^{2,7}$, Julien Guy ${ }^{8}$, Serge Monier ${ }^{2,9}$, Marjolaine Georges ${ }^{10}$, Audrey Large ${ }^{4}$, Auguste Dargent ${ }^{2,4}$, \\ Alexandre Guilhem ${ }^{11}$, Suzanne Mouries-Martin ${ }^{12}$, Jeremy Barben ${ }^{13}$, Belaid Bouhemad ${ }^{2,7}$, \\ Pierre-Emmanuel Charles ${ }^{2,4}$, Pascal Chavanet ${ }^{1,5,6}$, Christine Binquet ${ }^{2,5,6}$ and Lionel Piroth ${ }^{1,5,6}$ for the LYMPHONIE \\ Study Group
}

\section{Correction to: J TransI Medi (2020) 18:457 https://doi.org/10.1186/s12967-020-02646-9} Following publication of the original article [1], the authors identified an error in the author group. The investigators of the Lymphonie study group weren't tagged as collaborators. figure are published in this Correction article. The original article has been updated.

The collaborators' names are included in the 'Acknowledgements' section and listed below. The author group has been updated above and the original article [1] has been corrected.

The investigators of the LYMPHONIE study group are:

Pascal Andreu, François Aptel, Marie Labruyère, Sébastien Prin, Guillaume Beltramo, Philippe Bonniaud, Philip Bielefeld, Hervé Devilliers, Bernard Bonnotte, Marielle Buisson and Alain Putot.

The publisher apologises to the authors and the readers for the inconvenience caused by this error.

\section{Acknowledgements}

The authors thank all the investigators of the Lymphonie study group (Pascal Andreu, François Aptel, Marie Labruyère, Sébastien Prin (Department of Intensive

The original article can be found online at https://doi.org/10.1186/s1296 7-020-02646-9

*Correspondence: mathieu.blot@chu-dijon.fr

1 Infectious Diseases Department, Dijon Bourgogne University Hospital,

14 rue Paul Gaffarel, 21079 Dijon, France

Full list of author information is available at the end of the article
Care, Dijon Bourgogne University Hospital, Dijon, France); Guillaume Beltramo, Philippe Bonniaud (Department of Pneumology, Dijon Bourgogne University Hospital, Dijon, France); Philip Bielefeld, Hervé Devilliers (Department of Internal Medicine and Systemic Diseases, Dijon Bourgogne University Hospital, Dijon, France); Bernard Bonnotte (Department of Internal Medicine and Clinical Immunology, Dijon Bourgogne University Hospital, Dijon, France); Marielle Buisson (Infectious Diseases Department, Dijon Bourgogne University Hospital, Dijon, France); Alain Putot (Geriatrics Internal Medicine Department, Dijon Bourgogne University Hospital, Dijon, France). We thank the CIC-EC1432 (Alexandra LamotteFelin, Lydie Rossie and Delphine Pecqueur), the Intensive Care Medicine Research team (Solenne Villot, Mathilde Audry and Samantha Lima), the Cytometry core facility, Berengere Grammatico from the laboratory of virology and Shaliha Bechoua from the CRB (Centre de Ressource Biologique)). We also thank all the donors (crowdfunding; https://thellie.org/covid-19), and the patients and healthcare team. We thank Fiona Ecarnot, PhD (EA3920, University of Burgundy FrancheComté, Besançon, France) for proofreading and editing the manuscript.

\section{Author details}

${ }^{1}$ Infectious Diseases Department, Dijon Bourgogne University Hospital, 14 rue Paul Gaffarel, 21079 Dijon, France. ${ }^{2}$ Lipness Team, UMR1231 and LabEx LipSTIC, INSERM Research Center LNC, University of Burgundy, Dijon, France. ${ }^{3}$ Laboratory of Virology, Dijon Bourgogne University Hospital, Dijon, France. ${ }^{4}$ Department of Intensive Care, Dijon Bourgogne University Hospital, Dijon, France. ${ }^{5}$ Clinical Epidemiology Unit, INSERM, CIC1432 Dijon, France. ${ }^{6}$ Clinical Investigation Center, Clinical Epidemiology/Clinical Trials Unit, Dijon Bourgogne University Hospital, Dijon, France. ${ }^{7}$ Anesthesiology and Critical Care Department, Dijon Bourgogne University Hospital, Dijon, France. ${ }^{8}$ Dijon Bourgogne University Hospital, Hematobiology, Dijon, France. ${ }^{9}$ Cytometry Core Facility, University of Burgundy Franche-Comté, Dijon, France. ${ }^{10}$ Department of Pneumology, Dijon Bourgogne University Hospital, Dijon, France. ${ }^{11}$ Department of Internal Medicine and Clinical Immunology, Dijon Bourgogne University Hospital, Dijon, France. ${ }^{12}$ Department of Internal Medicine and Systemic Diseases, Dijon Bourgogne University Hospital, Dijon, France. ${ }^{13}$ Geriatrics Internal Medicine Department, Dijon Bourgogne University Hospital, Dijon, France.

Published online: 08 March 2021

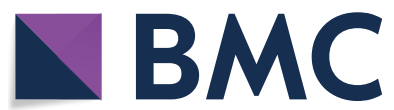

c The Author(s) 2021. This article is licensed under a Creative Commons Attribution 4.0 International License, which permits use, sharing, adaptation, distribution and reproduction in any medium or format, as long as you give appropriate credit to the original author(s) and the source, provide a link to the Creative Commons licence, and indicate if changes were made. The images or other third party material in this article are included in the article's Creative Commons licence, unless indicated otherwise in a credit line to the material. If material is not included in the article's Creative Commons licence and your intended use is not permitted by statutory regulation or exceeds the permitted use, you will need to obtain permission directly from the copyright holder. To view a copy of this licence, visit http://creativecommons.org/licenses/by/4.0/. The Creative Commons Public Domain Dedication waiver (http://creativecommons.org/publicdomain/zero/1.0/) applies to the data made available in this article, unless otherwise stated in a credit line to the data. 


\section{Reference}

1. Blot M, Bour J-P, Quenot JP, Bourredjem A, Nguyen M, Guy J, Monier S, Georges M, Large A, Dargent A, Guilhem A, Mouries-Martin S, Barben J, Bouhemad B, Charles P-E, Chavanet P, Binquet C, Piroth L, the LYMPHONIE Study Group. The dysregulated innate immune response in severe COVID-19 pneumonia that could drive poorer outcome. J Transl Med. 2020;18:457. https://doi.org/10.1186/s12967-020-02646-9.

\section{Publisher's Note}

Springer Nature remains neutral with regard to jurisdictional claims in published maps and institutional affiliations. 